\title{
Oxidative photo-catalytic destruction of eosine with the application of iron-contalning metal-ceramic composites with additive complex-forming reagents
}

\author{
(C) Anna A. Damzina ${ }^{1}$, Lidia N. Skvortsova, ${ }^{1}{ }^{+}$and Konstantin A. Bolgaru ${ }^{2 *}$ \\ ${ }^{1}$ Department of Analytical Chemistry. National Research Tomsk State University. 36 Lenin Ave., \\ Tomsk, 634050 Russia. Phone: +7 (908) 958-81-35, (913) 887-55-39. \\ E-mail: anna.damzina@yandex.ru ; lnskvorcova@inbox.ru \\ ${ }^{2}$ Tomsk Scientific Center of the Siberian Branch of the Russian Academy of Sciences (SBRAS). \\ Academichesky Ave., 10/3. Tomsk, 634021. Russia. Phone: +7 (923) 407-70-84. \\ E-mail: kbolgaru2008@yandex.ru
}

\begin{abstract}
*Supervising author; ${ }^{+}$Corresponding author
Keywords: eosin, iron-containing metal-ceramic composites, homogeneous catalysis, ultraviolet radiation, iron complex compounds.
\end{abstract}

\begin{abstract}
Iron-containing metal-ceramic composites based on nitrogen and sialon nitrides, obtained by the method of self-propagated synthesis were studied in the process of photocatalytic oxidative destruction of eosin. The phase composition of the samples was established by the X-ray diffraction method. It was shown that, along with the main phases, the ceramic matrix of materials contains the phases of semiconductors: (SiC, TiN). The indicator method of Hammet and Tanabe assessed the surface acid-base centers of the composites. It was established that a large sorption of the dye is characteristic of samples based on silicon nitride and sialon and is associated with the participation of active Brensted acid sites. The photocatalytic activity of ironcontaining composites was studied in the presence of $\mathrm{H}_{2} \mathrm{O}_{2}$ (photo-Fenton system), $\mathrm{H}_{2} \mathrm{O}_{2}$ and EDTA (peroxide-ferriccomplexon system), $\mathrm{H}_{2} \mathrm{O}_{2}$ and tartaric acid (peroxide-ferritartrate system). It was shown that the degree of oxidative destruction of eosin is significantly higher with the participation of $\mathrm{Fe}$ (II, III) complexes with EDTA and tartaric acid, than Fe(II, III) aquacomplexes in the photo-Feton system. The high activity of composites containing the semiconductor phase of titanium nitride (TiN) is due to the combination of homogeneous and heterogeneous catalysis with the participation of the ceramic matrix. The introduction of complexing agents shifts the optimal acidity ( $\mathrm{pH} \mathrm{2-4)} \mathrm{for} \mathrm{a} \mathrm{homogeneous} \mathrm{system} \mathrm{of} \mathrm{photo-Fenton} \mathrm{with} \mathrm{the}$ participation of iron(II, III) aqua complexes in the weakly acidic region ( $\mathrm{pH} 4-7)$ and leads to almost complete destruction of the dye in the peroxide-tartrate system.
\end{abstract}

\section{References}

[1] A.V. Zhelovitskaya, E.A. Ermolaeva, A.F. Dresvyannikov. Oxidation of organic compounds using a hydroxide radical generated in solutions by chemical and electrochemical methods. Bulletin of Kazan Technological University. 2008. No.6. P.211-229. (russian)

[2] M. Cheng, G. Zeng, D. Huang, C. Lai, P. Xu, C. Zhang, Y. Liu. Hydroxyl radicals based advanced oxidation processes (AOPs) for remediation of soils contaminated with organic compounds. Chemical. Engineering Journal. 2015. Vol.284. P.582-598.

[3] R. Munter. Advanced Oxidation Processes - Current Status and Prospects. Proceedings of the Estonian Academy of Sciences, Chemistry. 2001. Vol.50. No.2. P.59-80.

[4] L. Lomora, C. Draghici, Al. Enesca. Intermediary Compounds in Advanced Oxidation Processes for Wastewater Treatment. Bulletin of the Transilvania University of Braşov Series I: Engineering Sciences. 2011. Vol.4(53). No.1. P.51-58.

[5] A.R. Ribeiro, O.C. Nunes, M.F.R. Pereira, A.M.T. Silva. An Overview on the Advanced Oxidation Processes Applied for the Treatment of Water Pollutants Defined in the Recently Launched Directive 2013/39/EU. Environment International. 2015. Vol.75. P.33-51. 
[6] J. Donlagic, J. Levee. Comparison of Catalyzed and Noncatalyzed Oxidation of Azo Dye and Effect on Biodegradability. Environmental Science and Technology. 1998. Vol.32. No.9. P.1294-1302.

[7] W. Chen, X. Li, M. Liu, L. Li. Effective Catalytic Ozonation for Oxalic Acid Degradation with Bimetallic Fe-Cu-MCM-41: Operation Parameters and Mechanism. Journal of Chemical Technology and Biotechnology. 2017. Vol.92. No.11. P.2862-2869.

[8] L. Chen, D. Ding, C. Liu, H. Cai, Y. Qu, S. Yang, Y. Gao, T. Cai. Degradation of Norfloxacin by CoFe2O4-GO Composite Coupled with Peroxymonosulfate: A Comparative Study and Mechanistic Consideration. Chemical Engineering Journal. 2018. Vol.334. P.273-84.

[9] Q. Sun, L. Li, Yan H., X. Hong, K.S. Hui, Pan Zh. Influence of the Surface Hydroxyl Groups of $\mathrm{MnO}_{\mathrm{x}} / \mathrm{SBA}-15$ on Heterogeneous Catalytic Ozonation of Oxalic Acid. Chemical Engineering. Journal. 2014. Vol.242. P.348-356.

[10] N.S. Mishra, R. Reddy, A. Kuila, A. Rani, P. Mukherjee, A. Nawaz, S. Pichian. A Review Advanced Oxidation Processes for Effective Water Treatment. Current World Environment. 2017. Vol.12. No.3. P.470-490.

[11] L.N. Skvortsova, L.N. Chukhlomina, K.A. Bolgaru, V.N. Batalova, O.A. Shashkina. Iron-containing metal-ceramic composites for photocatalytic hydrogen generation from water-soluble pollutants. Advances of modern natural science Publ. 2017. No.12. P.9-15. (russian)

[12] Nitride Ceramics: Combustion Synthesis, Properties and Applications. Edited by A.A. Gromov and L.N. Chuklomina. Germania: Wiley-VCH. 2014. 360p.

[13] M.N. Chong, B. Jin, C.W.K. Chow, C. Saint. Recent developments in photocatalytic water treatment technology: A rewiew. Water Research. 2010. Vol.44. P.2997-3027.

[14] A.M. Zainullin, L.F. Zainullina, G.M. Shafigullin, I.G. Shaikhiev, E.A. Dmitrieva. The influence of pH on the efficiency of wastewater treatment for production of lead trinitroresorcinate under the reaction conditions of fenton. Bulletin of the Technological University, Kazan. 2017. Vol.20. No.13. P.123-127. (russian)

[15] I.G. Orletsky, M.I. Ilaschuk, V.V. Brus, P.D. Maryachuk, M.M. Solovan, Z.D. Kovalyuk. Electrical and photoelectric properties of TiN/p-InSe heterostructures. Physics and technology of semiconductors. 2016. Vol.50. No.3. P.339-343. (russian)

[16] L. Clarizia, D. Russoa, I. Di Sommab, R. Marottaa, R. Andreozzi. Homogeneous photo-Fenton processes at near neutral pH: A review. Applied Catalysis B: Environmental 209. 2017. P.358-371.

[17] A.P. Nechiporenko. Donor-acceptor surface properties of solid-phase systems. Indicator method. Doe Publ. 2017. 2843p. (russian)

[18] E.A. Pakhnutova, Yu.G. Slizhov. Acid-base surface properties of gas chromatography sorbents with grafted layers of metal chelates. Journal of physical chemistry. 2014. Vol.88. No.7-8. P.1228-1232. (russian)

[19] S.I. Metelitsa, E.V. Kireeva, V.V. Nemikhin, S.V. Kachin, V.N. Losev, S.A. Sagalakov. Extractionfluorimetric determination of codeine in human urine. Analytics and Control. 2017. Vol.21. No.4. P.315-321. (russian)

[20] Feng Wu, Nansheng Deng, E.M. Glebov, I.P. Pozdnyakov, V.P. Grivin, V.F. Plyusnin, N.M. Bazhin. Kinetics and mechanism of photolysis of the iron(III) complex with tartaric acid. Russian Chemical Bulletin, International Edition. 2007. Vol.56. No.5. P.900-903.

[21] A. Sychev. Homogeneous catalysis of iron compounds. Chisinau. 1988. 214p. (russian)

[22] A.A. Nemodruk, E.V. Bezrogova. Photochemical reactions in analytical chemistry. Moscow: Chemistry Publ. 1972. 190p. (russian) 